\title{
Intake of arachidonic acid-containing lipids in adult humans: dietary surveys and clinical trials
}

\author{
Hiroshi Kawashima
}

\begin{abstract}
Long-chain polyunsaturated fatty acids (LCPUFAs) have important roles in physiological homeostasis. Numerous studies have provided extensive information about the roles of n-3 LCPUFA, such as docosahexaenoic acid and eicosapentaenoic acid. Arachidonic acid (ARA) is one of the major n-6 LCPUFAs and its biological aspects have been well studied. However, nutritional information for ARA is limited, especially in adult humans. This review presents a framework of dietary ARA intake and the effects of ARA supplementation on LCPUFA metabolism in adult humans, and the nutritional significance of ARA and LCPUFA is discussed.
\end{abstract}

Keywords: Arachidonic acid, Dietary survey, Docosahexaenoic acid, Eicosapentaenoic acid, Long-chain polyunsaturated fatty acid

\section{Background}

Long-chain polyunsaturated fatty acids (LCPUFAs) are the main constituents of biomembranes and have important roles in physiological homeostasis. LCPUFAs consist of two individual series, namely, $\mathrm{n}-6$ and $\mathrm{n}-3$ series. Humans cannot synthesize n- 6 and n-3 PUFAs de novo, and convert linoleic acid (LA) and alpha-linolenic acid (ALA) obtained from foods to $n-6$ and n-3 LCPUFAs, respectively. LCPUFAs in the body are consequently derived from both the conversion of LA or ALA and the direct intake of respective LCPUFAs (Fig. 1). The major $n-6$ LCPUFA is arachidonic acid (ARA), and the major $n-3$ LCPUFAs are docosahexaenoic acid (DHA) and eicosapentaenoic acid (EPA). The importance of dietary intake of DHA and EPA has been extensively studied [1-3], but there is limited information for n-6 LCPUFA. Studies of ARA have focused on biological aspects, and many lipid mediators from ARA have been discovered and contribute to its medical application [4-9]. However, little attention has been paid to the dietary intake and clinical effects of ARA itself in adult humans [10], although the knowledge in infant nutrition has progressed exceptionally [11, 12]. Recently, the efficacy of ARA supplementation has been

Correspondence: hiroshi_kawashima@suntory.co.jp

Research Institute, Suntory Global Innovation Center Ltd., 8-1-1 Seikadai, Seika, Kyoto 619-0284, Japan

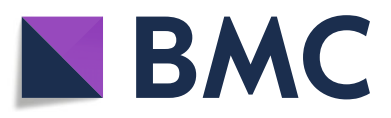

reported in the fields of cognitive attention and memory [13-15], mood states [16], coronary circulation [17] and cirrhosis $[18,19]$; and further nutritional understanding of ARA intake is expected.

The aim of this review is to provide an overview of the impact of ARA intake in adult humans. The author outlines the dietary intake of ARA from daily foods in adult humans of various countries, and reviews clinical trials of supplementation of ARA-containing lipids.

\section{Food sources of ARA}

ARA is found only in animal-derived foods because plants cannot synthesize C-20 LCPUFAs. The main food sources of ARA are meat, poultry, eggs, fish and dairy foods, as shown in Table $1[20,21]$. ARA is contained in most animal foods [22, 23]; however, the contents of ARA are moderate, $<200 \mathrm{mg}$ per $100 \mathrm{~g}$ of these foods, revealing the wide but small distribution of ARA in major animal foods. This is in stark contrast to the case of DHA/EPA. DHA/ EPA is only found in seafood, however the content of DHA/EPA reaches from several hundred mg to more than $1 \mathrm{~g}$ per $100 \mathrm{~g}$ of fish. These data suggest that ARA intake may fluctuate less with the intake of certain animal food groups, in contrast to the case of DHA/EPA in fish.

Table 2 shows the contribution of each food to ARA intake [24-28]. The proportion of meat and poultry is

(C) The Author(s). 2019 Open Access This article is distributed under the terms of the Creative Commons Attribution 4.0 International License (http://creativecommons.org/licenses/by/4.0/), which permits unrestricted use, distribution, and reproduction in any medium, provided you give appropriate credit to the original author(s) and the source, provide a link to the Creative Commons license, and indicate if changes were made. The Creative Commons Public Domain Dedication waiver (http://creativecommons.org/publicdomain/zero/1.0/) applies to the data made available in this article, unless otherwise stated. 


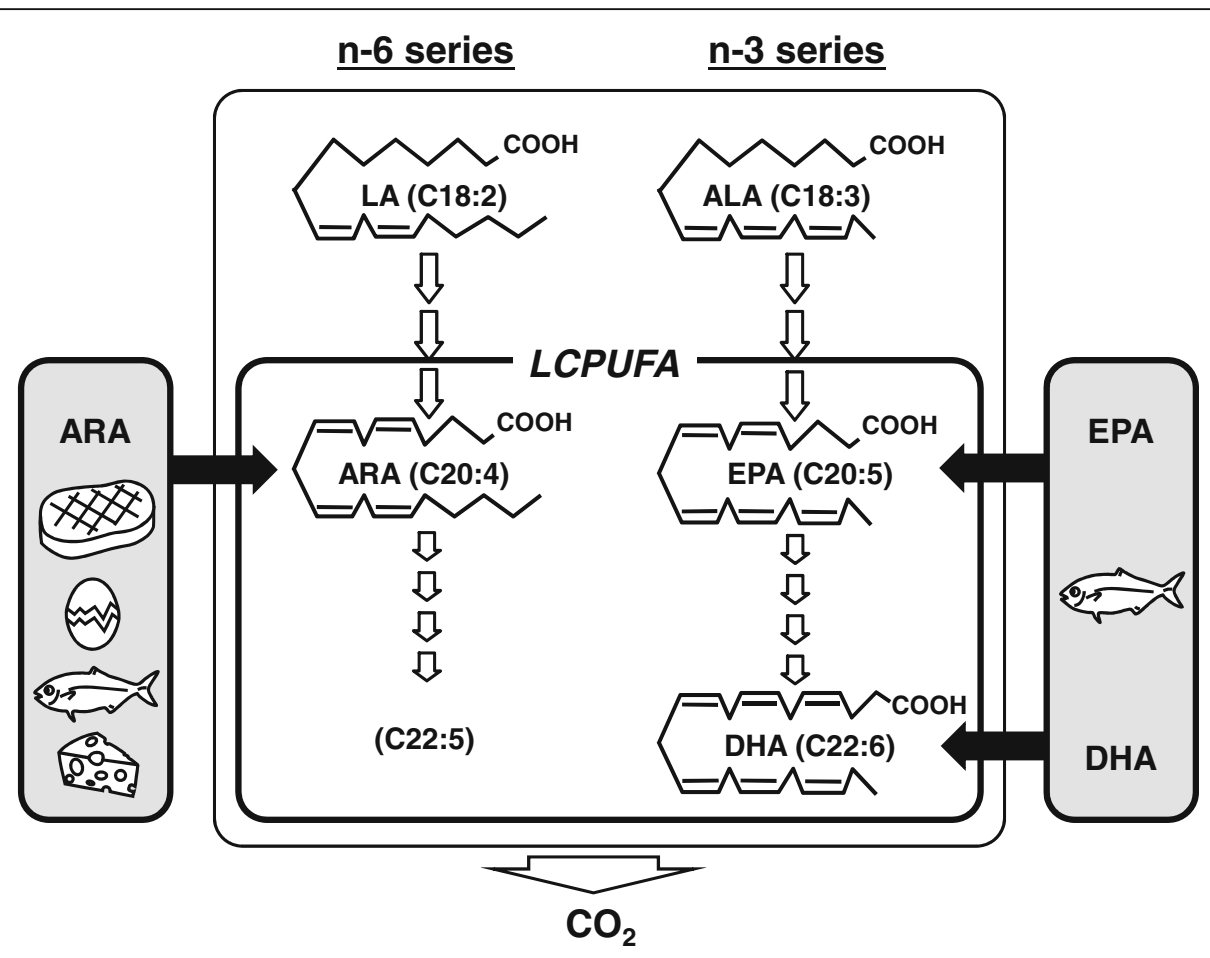

Fig. 1 Scheme of long-chain polyunsaturated fatty acid (LCPUFA) metabolism. LCPUFA in the body has two origins. One is the direct incorporation from dietary animal foods, and the other is the biosynthesis from n-6 or n-3 precursor PUFA, linoleic acid (LA) or a-linolenic acid (ALA), respectively. All the fatty acids including LCPUFA are mainly metabolized to $\mathrm{CO}_{2}$ by $\beta$-oxidation and excreted in the breath

high (43-62\%) in Europe [24, 25] and the United States [26], but is only $20-30 \%$ in Japan [27] and Korea [28]. The contribution of eggs is high in Japan. Fish and seafood, the main sources of DHA/EPA, are also significant sources of ARA (4.9-12.2\%) in all the countries. In elderly Japanese, the contribution of fish to ARA intake reached approximately $30 \%$ and was equal to that of meat [29]. It is equivocal that foods of plant origin are described as contributors to ARA intake in some studies (potato, rice and pasta, 7.1\% [25]; nuts. 9\% [26]), as these plants cannot synthesize ARA or C-20 LCPUFAs. This suggests that the qualitative or quantitative accuracy of ARA content in food composition tables is not always complete, which may be one of the reasons why the calculation of ARA intake seems inaccurate in some cases, as described below.

\section{Dietary intake of ARA}

Dietary intakes of LCPUFA in 175 countries were estimated using food balance sheets from the Food and Agriculture Organization and food composition tables [30]. The calculated ARA intakes ranged from 101 to $351 \mathrm{mg} /$ day in advanced countries, and $44-331 \mathrm{mg} /$ day in developing countries. This is a useful calculation derived from the statistical data of international agriculture and trade; however, it is only an estimation for individual countries and is not based on accurate amounts of
LCPUFAs derived from direct measurements of food consumption of individuals or specific groups. The author therefore reviewed the studies to investigate the amount of dietary ARA using nutritional survey methods.

Table 3 shows data compiled from surveys of more than 1000 healthy adults in a study and published from January 2001 [24, 25, 31-41]. The data were obtained from various areas, i.e., Europe, North America, Africa, Asia and Oceania. The amounts of dietary ARA intake range widely from 9 to $290 \mathrm{mg} /$ day. The large differences may be attributable to the survey method or the dietary habits in individual countries. First, with respect to the survey methods, it is notable that similar amounts of ARA intake were reported in four studies [24, 32, 38, 40] using dietary record (DR) or 24-h diet recall (169230 (male) and 117-160 (female) mg/day). Generally, the quantitative accuracy of DR or 24-h recall is thought to be superior to that of the food frequency questionnaire (FFQ). Most of the other studies using DR or 24-h recall with smaller numbers of participants also reported that ARA intakes were around $100 \mathrm{mg} /$ day or more, although there are some exceptions (Table 4) [28, 42-48]. These studies suggest that ARA intake, at least in advanced countries, is $100-250 \mathrm{mg} /$ day for normal healthy adults. This is a similar but narrower range compared to the calculation from the statistical data described above 
Table 1 Content of ARA and the other fatty acids per $100 \mathrm{~g}$ edible portion of animal foods

\begin{tabular}{|c|c|c|c|c|c|c|c|c|}
\hline \multirow[t]{2}{*}{ Food group } & \multirow[t]{2}{*}{ Ref. $^{a}$} & \multirow{2}{*}{$\begin{array}{l}\text { Total fat } \\
(\mathrm{mg})\end{array}$} & \multicolumn{6}{|c|}{ Fatty acids $(\mathrm{mg})^{\mathrm{b}}$} \\
\hline & & & $\mathrm{PA}$ & $\mathrm{OA}$ & LA & ARA & EPA & $\overline{\mathrm{DHA}}$ \\
\hline \multicolumn{9}{|l|}{ Meats and poultry } \\
\hline Pork, loin, whole, lean and fat, raw & C & 12,580 & 2720 & 5140 & 1110 & 80 & 0 & 0 \\
\hline Pork, medium type breed, loin, lean and fat, raw & J & 22,600 & 5600 & 9100 & 1900 & 68 & 0 & 12 \\
\hline Chicken, broiler, thigh, meat and skin, raw & C & 16,610 & 3511 & 5832 & 3096 & 104 & 4 & 7 \\
\hline Chicken, broiler, thigh, meat with skin, raw & 」 & 14,200 & 3300 & 5800 & 1600 & 79 & 1 & 7 \\
\hline Beef, hip, inside (top) round steak, boneless, lean, raw & C & 2210 & 520 & 910 & 120 & 40 & 0 & 0 \\
\hline Beef, inside round, lean, raw & J & 4300 & 890 & 1500 & 120 & 24 & 4 & 1 \\
\hline \multicolumn{9}{|l|}{ Eggs } \\
\hline Chicken, whole, fresh or frozen, raw & C & 10,010 & 2218 & 3810 & 1109 & 156 & 2 & 72 \\
\hline Hen, whole, raw & J & 10,300 & 2100 & 3500 & 1300 & 150 & 0 & 120 \\
\hline \multicolumn{9}{|l|}{ Fishes and seafoods } \\
\hline Salmon, pink (humpback), raw & C & 6700 & 1044 & 1108 & 102 & 127 & 547 & 859 \\
\hline Pink salmon, raw & J & 6600 & 790 & 920 & 81 & 31 & 400 & 690 \\
\hline Flatfish (flounder or sole or plaice), raw & C & 1930 & 282 & 358 & 45 & 30 & 137 & 108 \\
\hline Righteye flounder, brown sole, raw & 」 & 1300 & 150 & 140 & 10 & 50 & 100 & 72 \\
\hline Sardine, pacific, canned in tomato sauce, drained with bones & C & 10,450 & 1738 & 1851 & 123 & 190 & 532 & 864 \\
\hline Sardine, Japanese pilchard, canned products, in tomato sauce & J & 10,800 & 1900 & 1200 & 140 & 160 & 1300 & 1100 \\
\hline \multicolumn{9}{|l|}{ Milk and dairy products } \\
\hline Cheese, cream & C & 34,240 & 8497 & 7923 & 1032 & 50 & 0 & 0 \\
\hline Cheese, cream & J & 33,000 & 8700 & 6400 & 570 & 38 & 20 & 6 \\
\hline
\end{tabular}

${ }^{a}$ C, Canadian nutrient file version 2015 [20]; J, Standard tables of food composition in Japan 2015 (seventh revised edition) [21]

${ }^{b} P A$ palmitic acid, OA oleic acid, LA linoleic acid, ARA arachidonic acid, EPA eicosapentaenoic acid, DHA docosahexaenoic acid

[30]. ARA intake in the tens of mg per day reported in some surveys is similar to or less than that of American vegetarians (3-44 mg/day) [37], and seems too low. Similar results were reported in the other studies with limited numbers of participants in Germany [49], Norway [50], Canada [51, 52] and Japan [27, 29, 53, 54]. Studies reporting that ARA intake is several $\mathrm{mg} /$ day are likely to contain errors in their calculation methods. To accurately assess the amount of ARA intake, it may be important to reexamine and revise the ARA content reported in various food composition tables.

Second, with respect to dietary habits in individual countries, it is expected that ARA intake is associated with the amount of animal food intake. This is strongly suggested by the study of vegetarians, where the strictness of animal food avoidance is proportional to the decrease in ARA intake [37]. Although a similar situation may be infrequent in advanced countries, it

Table 2 Food sources of ARA (\% of the total ARA intake) ${ }^{a}$

\begin{tabular}{|c|c|c|c|c|c|}
\hline Food group & France [24] & UK [25] & USA [26] & Japan [27] & Korea [28] \\
\hline Meats and poultry & 50.3 & 62.3 & 43 & 22.5 & 28.4 \\
\hline Eggs & 16.9 & 11.1 & 19 & 47.2 & 17.9 \\
\hline Fishes and seafoods & 11.1 & 4.9 & 9 & 11.1 & 12.2 \\
\hline Milk and dairy products & 1.1 & $n d^{b}$ & nd & 3.0 & 14.3 \\
\hline Sweet product & 11.6 & nd & nd & nd & nd \\
\hline \multicolumn{6}{|l|}{ Plant origin } \\
\hline Cereals, fruit and vegetable & 2.9 & nd & nd & nd & nd \\
\hline Potato, rice and pasta & nd & 7.1 & nd & nd & nd \\
\hline Nuts & 0.0 & nd & 9 & nd & nd \\
\hline
\end{tabular}

Total of each percentage does not reach $100 \%$ due to lack of the minor contributors

${ }^{a}$ Original data are classified to the nearest food group

${ }^{\mathrm{b}}$ nd not described 
Table 3 Dietary survey of intake of ARA, EPA and DHA in adult humans (> 1000 participants in a study and from January 2001)

\begin{tabular}{|c|c|c|c|c|c|c|c|c|c|}
\hline \multirow[t]{2}{*}{ Country } & \multicolumn{4}{|c|}{ Participant } & \multirow{2}{*}{$\begin{array}{l}\text { Dietary } \\
\text { survey }^{c}\end{array}$} & \multicolumn{3}{|c|}{ LCPUFA intake $(\mathrm{mg} / \text { day })^{d}$} & \multirow[t]{2}{*}{ Ref. } \\
\hline & $\overline{S e x^{a}}$ & Age $(y)^{b}$ & Other classification & $\mathrm{N}$ & & $\overline{\text { ARA }}$ & EPA & $\mathrm{DHA}$ & \\
\hline \multicolumn{10}{|l|}{ Europe } \\
\hline \multirow[t]{2}{*}{ Finland } & $M \& F$ & $30-49$ & - & 1212 & FFQ & $95 \pm 0.84^{e}$ & $160 \pm 3.1^{\mathrm{e}}$ & $420 \pm 8.7^{e}$ & [31] \\
\hline & & $50-79$ & - & 980 & & $97 \pm 1.1^{\mathrm{e}}$ & $190 \pm 4.6^{\mathrm{e}}$ & $510 \pm 13^{e}$ & \\
\hline \multirow[t]{2}{*}{ France } & M & $45-63$ & - & 2099 & ten 24-h DR & $204 \pm 66$ & $150 \pm 112$ & $273 \pm 191$ & [24] \\
\hline & $\mathrm{F}$ & $35-63$ & - & 2785 & & $152 \pm 49$ & $118 \pm 94$ & $226 \pm 171$ & \\
\hline \multirow[t]{4}{*}{ Germany } & M & $45-65$ & Heidelberg & 1013 & 24-h recall & $230 \pm 250$ & $100 \pm 300$ & $190 \pm 480$ & [32] \\
\hline & & & Potsdam & 1032 & & $230 \pm 250$ & $130 \pm 380$ & $210 \pm 490$ & \\
\hline & $\mathrm{F}$ & $35-64$ & Heidelberg & 1078 & & $160 \pm 190$ & $70 \pm 230$ & $140 \pm 330$ & \\
\hline & & & Potsdam & 898 & & $140 \pm 160$ & $80 \pm 230$ & $140 \pm 280$ & \\
\hline Spain & $\mathrm{F}$ & $20-79$ & - & 1865 & FFQ & $290 \pm 110$ & $220 \pm 90$ & $300 \pm 120$ & [33] \\
\hline United Kingdom & $M \& F$ & $16-79$ & - & 1455 & FFQ & $9^{f}$ & $290^{f}$ & $380^{f}$ & [25] \\
\hline \multicolumn{10}{|l|}{ North America } \\
\hline United States & $\mathrm{F}$ & $>45$ & Health Professional & 37,547 & FFQ & $70^{f}$ & $20^{f}$ & $60^{f}$ & [34] \\
\hline United States & $M \& F$ & $>30$ & - & 2837 & FFQ & $120 \pm 80$ & $45 \pm 50$ & $82 \pm 73$ & [35] \\
\hline United States & $\mathrm{F}$ & $<65$ & - & 1500 & FFQ & $70 \pm 60$ & $40 \pm 50$ & $90 \pm 90$ & [36] \\
\hline \multirow[t]{5}{*}{ United States \&Canada } & M\&F & $>30$ & Nonvegetarian & 33,634 & FFQ & $84 \pm 0.3^{e}$ & $n d^{9}$ & $182 \pm 1.2^{\mathrm{e}}$ & [37] \\
\hline & & & Semi-vegetarian & 4042 & & $27 \pm 0.7^{e}$ & nd & $70 \pm 3.6^{\mathrm{e}}$ & \\
\hline & & & Pesco vegetarian & 6583 & & $44 \pm 0.6^{\mathrm{e}}$ & nd & $187 \pm 2.8^{\mathrm{e}}$ & \\
\hline & & & Lacto-ovo vegetarian & 21,799 & & $13 \pm 0.3^{e}$ & nd & $34 \pm 1.5^{\mathrm{e}}$ & \\
\hline & & & Strict vegetarian & 5694 & & $3 \pm 0.6^{e}$ & nd & $18 \pm 3^{e}$ & \\
\hline \multicolumn{10}{|l|}{ Africa, Asia and Oceania } \\
\hline \multirow[t]{2}{*}{ Australia } & M & $>19$ & - & 5081 & 24-h recall & $191 \pm 2^{e}$ & $91 \pm 3^{e}$ & $117 \pm 5^{\mathrm{e}}$ & [38] \\
\hline & $\mathrm{F}$ & $>19$ & - & 5770 & & $117 \pm 2^{\mathrm{e}}$ & $60 \pm 2^{e}$ & $83 \pm 3^{e}$ & \\
\hline China & $\mathrm{F}$ & $40-70$ & - & 74,943 & FFQ & $50^{f}$ & $n d^{h}$ & $n d^{h}$ & [39] \\
\hline \multirow[t]{8}{*}{ Japan } & M & $40-49$ & - & 241 & 3-day DR & $179 \pm 66$ & $233 \pm 211$ & $437 \pm 331$ & [40] \\
\hline & & $50-59$ & - & 268 & & $185 \pm 64$ & $368 \pm 296$ & $662 \pm 476$ & \\
\hline & & $60-69$ & - & 262 & & $182 \pm 63$ & $403 \pm 263$ & $718 \pm 422$ & \\
\hline & & $70-79$ & - & 243 & & $171 \pm 64$ & $390 \pm 257$ & $692 \pm 437$ & \\
\hline & $\mathrm{F}$ & $40-49$ & - & 263 & & $153 \pm 52$ & $217 \pm 185$ & $414 \pm 305$ & \\
\hline & & $50-59$ & - & 259 & & $148 \pm 51$ & $268 \pm 202$ & $487 \pm 322$ & \\
\hline & & $60-69$ & - & 261 & & $149 \pm 53$ & $300 \pm 196$ & $532 \pm 312$ & \\
\hline & & $70-79$ & - & 245 & & $144 \pm 55$ & $300 \pm 219$ & $525 \pm 340$ & \\
\hline \multirow[t]{4}{*}{ South Africa } & M & $>35$ & Rural & 333 & FFQ & $34^{f}$ & $38^{f}$ & $62^{f}$ & [41] \\
\hline & & & Urban & 393 & & $102^{f}$ & $61^{f}$ & $101^{f}$ & \\
\hline & $\mathrm{F}$ & $>35$ & Rural & 633 & & $33^{f}$ & $33^{f}$ & $52^{f}$ & \\
\hline & & & Urban & 591 & & $94^{f}$ & $46^{f}$ & $83^{f}$ & \\
\hline
\end{tabular}

${ }^{\mathrm{a}} M$ male, $F$ female

${ }^{\mathrm{b}}$ Mean or range

${ }^{c} F F Q$ food frequency questionnaire, $D R$ diet record

${ }^{\mathrm{d}}$ Data are the mean \pm SD without annotation. Original data are rounded to nearest $\mathrm{mg}$

eMean \pm SE

${ }^{\mathrm{f}}$ Median

${ }^{\mathrm{g}}$ nd not described

${ }^{\mathrm{h}}$ Median of $(\mathrm{EPA}+\mathrm{DHA})$ is $70 \mathrm{mg} / \mathrm{d}$ 
Table 4 Dietary survey of intake of ARA, EPA and DHA in adult humans ( $<1000$ participants by DR or 24-h recall)

\begin{tabular}{|c|c|c|c|c|c|c|c|c|c|}
\hline \multirow[t]{2}{*}{ Country } & \multicolumn{4}{|c|}{ Participant } & \multirow[t]{2}{*}{ Dietary Survey ${ }^{c}$} & \multicolumn{3}{|c|}{ LCPUFA intake $(\mathrm{mg} / \text { day })^{d}$} & \multirow[t]{2}{*}{ Ref. } \\
\hline & $\operatorname{Sex}^{a}$ & Age $(y)^{b}$ & Other classification & $\mathrm{N}$ & & ARA & EPA & $\mathrm{DHA}$ & \\
\hline Bangladeshi & $\mathrm{F}$ & $16-50$ & Mothers of children 2-4 y & 455 & 24-h recall & 40 & 30 & 30 & [42] \\
\hline Belgium & $\mathrm{F}$ & $18-39$ & - & 641 & 2-day DR & $56 \pm 47$ & $78 \pm 156$ & $131 \pm 247$ & [43] \\
\hline Brazil & $\mathrm{F}$ & $18-35$ & Pregnant women & 41 & 24-h recall & 90 & 0.2 & 20 & [44] \\
\hline \multirow[t]{2}{*}{ China } & $\mathrm{F}$ & 27.0 & Changzhou area & 82 & 7-day DR & $110 \pm 40$ & $50 \pm 40$ & $40 \pm 60$ & {$[45]$} \\
\hline & & 27.8 & Wenzhou area & 20 & & $140 \pm 60$ & $120 \pm 130$ & $180 \pm 230$ & \\
\hline Japan & $\mathrm{F}$ & $40-49$ & Spring season & 71 & 7-day DR & $134 \pm 39$ & $277 \pm 13$ & $755 \pm 357$ & [46] \\
\hline \multirow[t]{2}{*}{ Korea } & M & $30-85$ & - & 107 & 3-day DR & $135 \pm 161$ & $279 \pm 690$ & $172 \pm 1114$ & [28] \\
\hline & $\mathrm{F}$ & $30-85$ & - & 117 & & $99 \pm 116$ & $159 \pm 271$ & $235 \pm 1479$ & \\
\hline \multirow[t]{3}{*}{ South Africa } & $\mathrm{F}$ & 32.8 & Urban Northern Cape & 83 & 24-h recall & 97 & 33 & 54 & [47] \\
\hline & & 32.9 & Urban coastal Western Cape & 81 & & 105 & 36 & 67 & \\
\hline & & 34.8 & Rural Limpopo Province & 85 & & 39 & 8 & 24 & \\
\hline \multirow[t]{6}{*}{ United States } & M & 49 & Pakistan-origin & 106 & 24-h recall & $200 \pm 700$ & $30 \pm 70$ & $90 \pm 20$ & {$[48]$} \\
\hline & & 49 & India-origin & 34 & & $160 \pm 140$ & $10 \pm 10$ & $40 \pm 40$ & \\
\hline & & 46 & Bangladesh-origin & 34 & & $200 \pm 140$ & $200 \pm 30$ & $300 \pm 400$ & \\
\hline & $\mathrm{F}$ & 48 & Pakistan-origin & 117 & & $200 \pm 100$ & $40 \pm 100$ & $100 \pm 200$ & \\
\hline & & 49 & India-origin & 37 & & $100 \pm 100$ & $40 \pm 100$ & $70 \pm 200$ & \\
\hline & & 49 & Bangladesh-origin & 33 & & $200 \pm 100$ & $300 \pm 500$ & $400 \pm 800$ & \\
\hline
\end{tabular}

${ }^{\mathrm{a}} M$ male, $F$ female

${ }^{\mathrm{b}}$ Mean or range

' $F F Q$ food frequency questionnaire, $D R$ diet record

${ }^{\mathrm{d}}$ Data are the mean \pm SD or median. Original data are rounded to nearest $\mathrm{mg}$

may occur in developing countries. ARA intake was reported to be 33-34 [41] or $39 \mathrm{mg} / \mathrm{day}$ [47] in rural areas of South Africa, which is approximately one-third of that in respective urban areas. In any case, it is expected that additional high-quality nutritional data of dietary ARA intake in various countries and groups will accumulate.

\section{ARA source by fermentation technique}

Numerous studies for infant nutrition have clarified that DHA and ARA are present in breast milk, that infants themselves have only a weak ability to synthesize DHA and ARA endogenously from ALA and LA, and that addition of DHA and ARA to infant formula is preferred for development of infants [11, 12]. Fish oil is a good source for DHA, and has been used for an ingredient of infant formula. However, as described above, the contents of ARA are moderate in common foods. Since there was no practical source for ARA, a new ARA oil with high-quality was needed. In order to obtain oil with high ARA content for addition to infant formula, a microbial fermentation oil was developed in 1987 [55, 56]. The fungus Mortierella alpina accumulates large amounts of ARA-containing lipids in its cells [57], and an industrial production process for it has been established $[58,59]$. This oil has been used for infant formula worldwide [60]. At the same time, ARA oil is now used for adult humans, especially the elderly, making it possible to investigate the physiological roles and efficacy of ARA [61-68].

\section{Supplementation of ARA-containing lipids}

Table 5 summarizes the clinical trials reporting changes in ARA composition of blood in adult humans with ARA supplementation [16, 17, 19, 69-74]. The ARA-containing lipids of $M$. alpina were used for ARA supplementation in all nine studies. The conditions of the trials are different from each other. Doses of ARA as free ARA were 82.8$3600 \mathrm{mg} /$ day with or without DHA/EPA. Supplementation periods were from 14 days to 3 months. Fatty acid analyses were conducted using plasma phospholipids (PL) or red blood cells (RBC). Interestingly, the smallest dose of ARA $(82.8 \mathrm{mg} /$ day for 3 weeks $)$ resulted in a significant increase of ARA composition in plasma PL and RBC [69]. The second smallest dose of ARA (120 mg/day for 4 weeks) with DHA/EPA (300/100 mg/kg) also increased ARA composition of plasma PL [16]. These doses of ARA are equal to or less than the standard dietary ARA intake (100-250 mg/ day), as reviewed above. These data support that dietary ARA intake from daily foods should contribute to the increase or maintenance of plasma ARA composition, which may have been understated so far. All the doses of ARA increased blood ARA levels regardless of co-supplementation with DHA/EPA. Correlation between the dose of ARA 


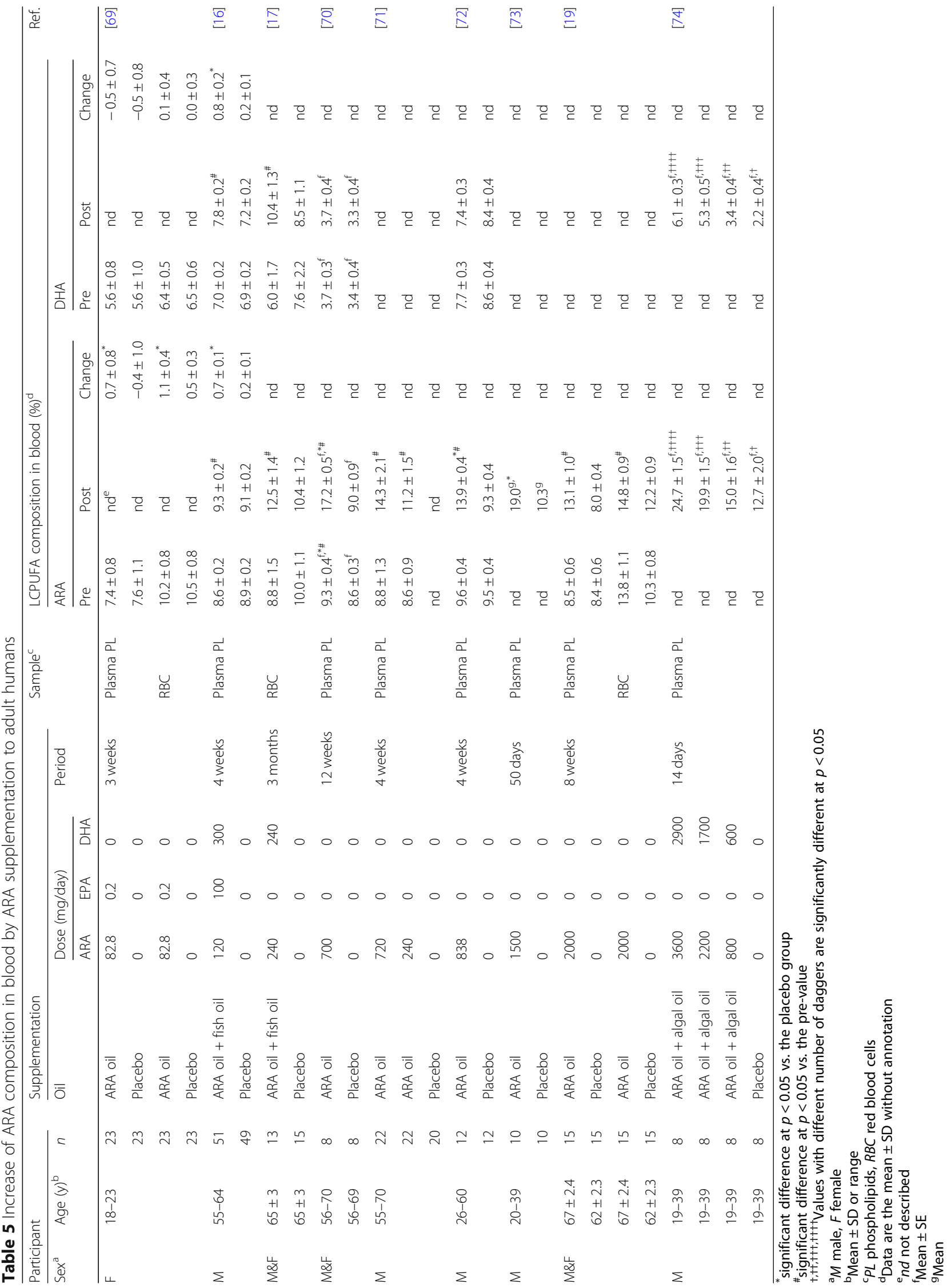




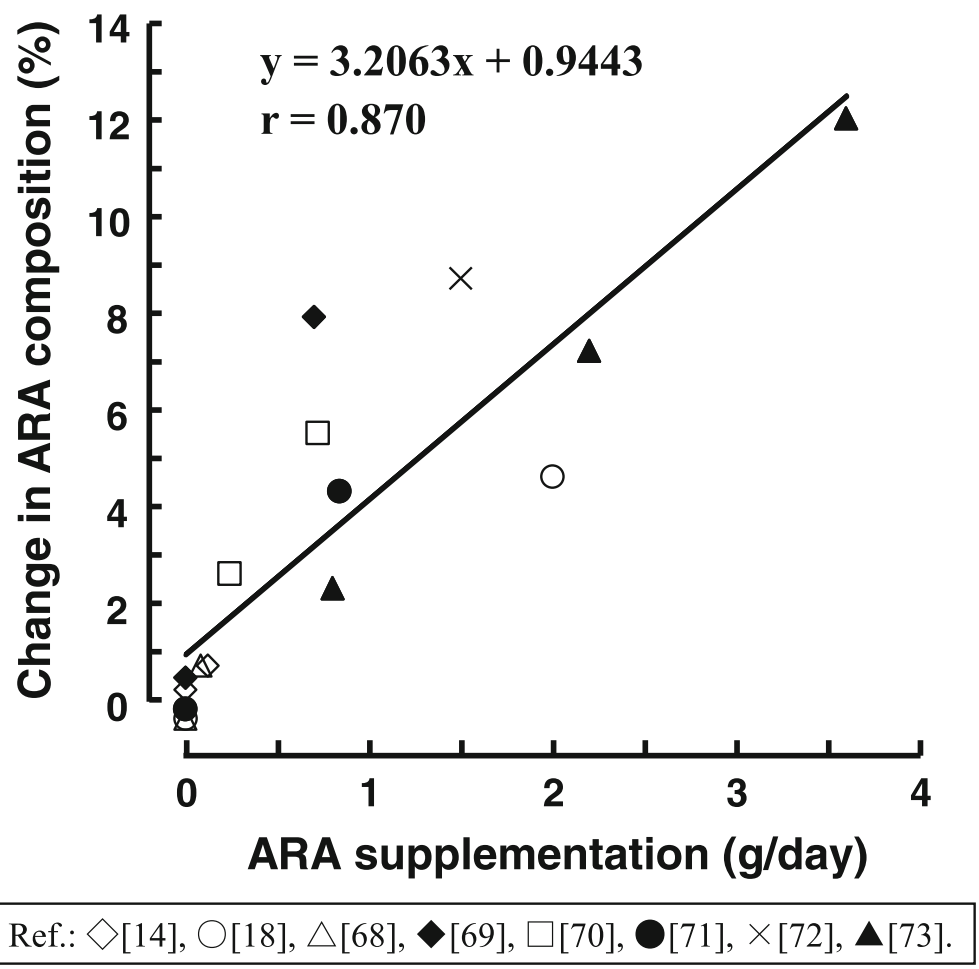

Fig. 2 Correlation between the dose of ARA supplementation and the change of plasma ARA composition. The change of plasma ARA composition was calculated from Table 5. Neither the number of participants, supplementation period nor the existence or non-existence of DHA/EPA was taken into account. Data from individual studies are indicated with the same symbol

supplementation and the change of plasma ARA composition is shown in Fig. 2. The increase in plasma ARA composition is dose-dependent over a range of $82-3600 \mathrm{mg} / \mathrm{kg}(r=0.87)$.

ARA supplementation does not result in decreased DHA/EPA composition as shown in Table 5. DHA/EPA composition was unchanged by $700 \mathrm{mg}$ [70] or $838 \mathrm{mg}$ [72] of ARA per day. In the same manner, 240 and $720 \mathrm{mg}$ [71] or $1500 \mathrm{mg}$ [73] of ARA per day did not change DHA/EPA composition. In contrast, it is well known that ARA composition is decreased by DHA/EPA supplementation $[75,76]$. Interestingly, it is commonly observed that ARA supplementation results in large decreases in LA composition [71-74]. It appears that the capacity for exchange or retention in the body is in the following order DHA/EPA $>$ ARA $>$ LA. The substrate specificities of various acyl transfer reactions are thought to be related to this phenomenon; however, the details are unclear. It is important to consider the mechanism of LCPUFA metabolism, which requires further clarification.

\section{Conclusion}

This review of dietary surveys of ARA intake indicates that ARA is obtained from a wide variety of animal foods, such as meat, poultry, egg, fish and dairy foods, and that the amount of ARA intake is $100-250 \mathrm{mg} /$ day in advanced counties. Meanwhile, ARA intake may be in the tens of $\mathrm{mg} /$ day in developing countries. The review also demonstrates that ARA supplementation (82 or $120 \mathrm{mg} /$ day for 3-4 weeks) at a dose equal to or less than the dietary ARA intake increases plasma ARA composition; that plasma ARA composition is ARA dosedependently increased in the range of $82-3600 \mathrm{mg} /$ day; and that ARA supplementation decreases plasma LA composition, but not DHA/EPA composition. ARA intake from foods or supplementation is thought to have a great impact on LCPUFA metabolism. The continued accumulation of evidence from large and well-designed dietary surveys and clinical trials is expected to confirm this.

\section{Abbreviations \\ ALA: a-linolenic acid; ARA: Arachidonic acid; DHA: Docosahexaenoic acid; DR: Dietary record; EPA: Eicosapentaenoic acid; FFQ: Food frequency questionnaire; LA: Linoleic acid; LCPUFA: Long-chain polyunsaturated fatty acids; PL: Phospholipids; RBC: Red blood cells}

Acknowledgements

The author is grateful to Institute for Health Care Science, Suntory Wellness Ltd., for scientific suggestion to carry out this work.

Funding

This study received no external funding. 


\section{Availability of data and materials}

Not applicable.

\section{Author's contributions}

The author read and approved the final manuscript.

\section{Ethics approval and consent to participate}

Not applicable.

\section{Consent for publication}

Not applicable.

\section{Competing interests}

HK is an employee of the Suntory Holdings Group.

\section{Publisher's Note}

Springer Nature remains neutral with regard to jurisdictional claims in published maps and institutional affiliations.

Received: 15 February 2019 Accepted: 29 March 2019

Published online: 16 April 2019

\section{References}

1. Mozaffarian D, Wu JH. Omega-3 fatty acids and cardiovascular disease: effects on risk factors, molecular pathways, and clinical events. J Am Coll Cardiol. 2011;58(20):2047-67.

2. Serhan CN. Pro-resolving lipid mediators are leads for resolution physiology. Nature. 2014;510(7503):92-101.

3. Abdelhamid AS, Brown TJ, Brainard JS, Biswas P, Thorpe GC, Moore HJ, Deane KH, AlAbdulghafoor FK, Summerbell CD, Worthington HV, Song F, Hooper L. Omega-3 fatty acids for the primary and secondary prevention of cardiovascular disease. Cochrane Database Syst Rev. 2018;11:CD003177.

4. Narumiya S, Furuyashiki T. Fever, inflammation, pain and beyond: prostanoid receptor research during these 25 years. FASEB J. 2011;25(3):813-8.

5. Liu M, Yokomizo T. The role of leukotrienes in allergic diseases. Allergol Int. 2015;64(1):17-26.

6. Spector AA, Kim HY. Cytochrome P450 epoxygenase pathway of polyunsaturated fatty acid metabolism. Biochim Biophys Acta. 2015;1851(4): 356-65.

7. Baggelaar MP, Maccarrone M, van der Stelt M. 2-Arachidonoylglycerol: a signaling lipid with manifold actions in the brain. Prog Lipid Res. 2018;71:1-17.

8. Arita M. Mediator lipidomics in acute inflammation and resolution. J Biochem. 2012:152(4):313-9.

9. Ishii S, Nagase T, Shimizu T. Platelet-activating factor receptor. Prostaglandins Other Lipid Mediat. 2002;68-69:599-609.

10. Rett BS, Whelan J. Increasing dietary linoleic acid does not increase tissue arachidonic acid content in adults consuming Western-type diets: a systematic review. Nutr Metab (Lond). 2011;8:36.

11. Carlson SE, Colombo J. Docosahexaenoic acid and arachidonic acid nutrition in early development. Adv Pediatr Infect Dis. 2016;63(1):453-71.

12. Lien EL, Richard C, Hoffman DR. DHA and ARA addition to infant formula: current status and future research directions. Prostaglandins Leukot Essent Fatty Acids. 2018;128:26-40.

13. Kotani S, Sakaguchi E, Warashina S, Matsukawa N, Ishikura Y, Kiso Y, Sakakibara M, Yoshimoto T, Guo J, Yamashima T. Dietary supplementation of arachidonic and docosahexaenoic acids improves cognitive dysfunction. Neurosci Res. 2006;56(2):159-64.

14. Ishikura Y, Ikeda G, Akimoto K, Hata M, Kusumoto A, Kidokoro A, Kontani M, Kawashima H, Kiso Y, Koga Y. Arachidonic acid supplementation decreases P300 latency and increases P300 amplitude of event-related potentials in healthy elderly men. Neuropsychobiology. 2009;60(2):73-9.

15. Tokuda H, Sueyasu T, Kontani M, Kawashima H, Shibata H, Koga Y. Low doses of long-chain polyunsaturated fatty acids affect cognitive function in elderly Japanese men: a randomized controlled trial. J Oleo Sci. 2015;64(6):633-44.

16. Tokuda H, Sueyasu T, Kawashima H, Shibata H, Koga Y. Long-chain polyunsaturated fatty acid supplementation improves mood in elderly Japanese men. J Oleo Sci. 2017:66(7):713-21.

17. Oe H, Hozumi T, Murata E, Matsuura H, Negishi K, Matsumura Y, Iwata S, Ogawa K, Sugioka K, Takemoto Y, Shimada K, Yoshiyama M, Ishikura Y, Kiso Y, Yoshikawa J. Arachidonic acid and docosahexaenoic acid supplementation increases coronary flow velocity reserve in Japanese elderly individuals. Heart. 2008;94(3):316-21.

18. Miyamoto A, Wakabayashi $\mathrm{H}$, Watanabe A. Abnormality in fatty acid composition of gastric mucosal phospholipids in patients with liver cirrhosis and its correction with a polyunsaturated fatty acid-enriched soft oil capsule. J Gastroenterol Hepatol. 1997;12(9-10):644-52.

19. Pantaleo P, Marra F, Vizzutti F, Spadoni S, Ciabattoni G, Galli C, La Villa G, Gentilini P, Laffi G. Effects of dietary supplementation with arachidonic acid on platelet and renal function in patients with cirrhosis. Clin Sci (Lond). 2004;106(1):27-34.

20. Canadian nutrient file version 2015, Health Canada, Government of Canada. 2015. https://food-nutrition.canada.ca/cnf-fce/index-eng.jsp. Accessed 29 Jan 2019.

21. Standard tables of food composition in Japan 2015 (seventh revised edition), Ministry of Education, Culture, Sports, Science and Technology, Japan. 2015. http://www.mext.go.jp/a_menu/syokuhinseibun/1365451.htm. Accessed 29 Jan 2019.

22. Li D, Ng A, Mann NJ, Sinclair AJ. Contribution of meat fat to dietary arachidonic acid. Lipids. 1998;33(4):437-40.

23. Taber $\mathrm{L}$, Chiu $\mathrm{CH}$, Whelan J. Assessment of the arachidonic acid content in foods commonly consumed in the American diet. Lipids. 1998;33(12):1151-7.

24. Astorg P, Arnault N, Czernichow S, Noisette N, Galan P, Hercberg S. Dietary intakes and food sources of n- 6 and n-3 PUFA in French adult men and women. Lipids. 2004;39(6):527-35.

25. Theodoratou E, McNeill G, Cetnarskyj R, Farrington SM, Tenesa A, Barnetson R, Porteous M, Dunlop M, Campbell H. Dietary fatty acids and colorectal cancer: a case-control study. Am J Epidemiol. 2007;166(2):181-95.

26. Slattery ML, Potter JD, Duncan DM, Berry TD. Dietary fats and colon cancer: assessment of risk associated with specific fatty acids. Int J Cancer. 1997; 73(5):670-7.

27. Tokudome Y, Imaeda N, Ikeda M, Kitagawa I, Fujiwara N, Tokudome S. Foods contributing to absolute intake and variance in intake of fat, fatty acids and cholesterol in middle-aged Japanese. J Epidemiol. 1999;9(2):78-90.

28. Kim J, Kim YJ, Ahn YO, Paik HY, Ahn Y, Tokudome Y, Hamajima N, Inoue M, Tajima K. Contribution of specific foods to fat, fatty acids, and cholesterol in the development of a food frequency questionnaire in Koreans. Asia Pac J Clin Nutr. 2004;13(3):265-72.

29. Kawabata T, Hirota S, Hirayama T, Adachi N, Hagiwara C, Iwama N, Kamachi K, Araki E, Kawashima H, Kiso Y. Agerelated changes of dietary intake and blood eicosapentaenoic acid, docosahexaenoic acid, and arachidonic acid levels in Japanese men and women. Prostaglandins Leukot Essent Fatty Acids. 2011;84(5-6):131-7.

30. Forsyth S, Gautier S, Salem N Jr. Global estimates of dietary intake of docosahexaenoic acid and arachidonic acid in developing and developed countries. Ann Nutr Metab. 2016;68(4):258-67.

31. Jauhiainen $L$, Ylöstalo $P$, Männistö $S$, Kanerva N, Knuuttila M, Suominen AL. Periodontal condition in relation to intake of omega-3 and omega- 6 polyunsaturated fatty acids. J Clin Periodontol. 2016;43(11):901-8.

32. Linseisen J, Schulze MB, Saadatian-Elahi M, Kroke A, Miller AB, Boeing H. Quantity and quality of dietary fat, carbohydrate, and fiber intake in the German EPIC cohorts. Ann Nutr Metab. 2003:47(1):37-46.

33. Lavado-García J, Roncero-Martin R, Moran JM, Pedrera-Canal M, Aliaga I, LealHernandez O, Rico-Martin S, Canal-Macias ML. Long-chain omega-3 polyunsaturated fatty acid dietary intake is positively associated with bone mineral density in normal and osteopenic Spanish women. PLoS One. 2018;13(1): e0190539.

34. Lin J, Zhang SM, Cook NR, Lee IM, Buring JE. Dietary fat and fatty acids and risk of colorectal cancer in women. Am J Epidemiol. 2004;160(10): 1011-22.

35. de Oliveira Otto MC, Wu JH, Baylin A, Vaidya D, Rich SS, Tsai MY, Jacobs DR $\mathrm{Jr}$, Mozaffarian D. Circulating and dietary omega-3 and omega-6 polyunsaturated fatty acids and incidence of CVD in the Multi-Ethnic Study of Atherosclerosis. J Am Heart Assoc. 2013;2(6):e000506.

36. Khankari NK, Bradshaw PT, Steck SE, He K, Olshan AF, Shen J, Ahn J, Chen Y, Ahsan H, Terry MB, Teitelbaum SL, Neugut Al, Santella RM, Gammon MD. Polyunsaturated fatty acid interactions and breast cancer incidence: a population-based case-control study on Long Island, New York. Ann Epidemiol. 2015;25(12):929-35.

37. Rizzo NS, Jaceldo-Siegl K, Sabate J, Fraser GE. Nutrient profiles of vegetarian and nonvegetarian dietary patterns. J Acad Nutr Diet. 2013;113(12):1610-9.

38. Howe P, Meyer B, Record S, Baghurst K. Dietary intake of long-chain omega3 polyunsaturated fatty acids: contribution of meat sources. Nutrition. 2006; 22(1):47-53. 
39. Murff HJ, Shu XO, Li H, Dai Q, Kallianpur A, Yang G, Cai H, Wen W, Gao YT, Zheng W. A prospective study of dietary polyunsaturated fatty acids and colorectal cancer risk in Chinese women. Cancer Epidemiol Biomark Prev. 2009;18(8):2283-91.

40. Otsuka R, Kato Y, Imai T, Ando F, Shimokata H. Higher serum EPA or DHA, and lower ARA compositions with age independent fatty acid intake in Japanese aged 40 to 79. Lipids. 2013;48(7):719-27.

41. Richter M, Baumgartner J, Wentzel-Viljoen E, Smuts CM. Different dietary fatty acids are associated with blood lipids in healthy south African men and women: the PURE study. Int J Cardiol. 2014;172(2):368-74.

42. Yakes EA, Arsenault JE, Munirul Islam M, Hossain MB, Ahmed T, Bruce German J, Gillies LA, Shafiqur Rahman A, Drake C, Jamil KM, Lewis BL, Brown KH. Intakes and breast-milk concentrations of essential fatty acids are low among Bangladeshi women with 24-48-month-old children. Br J Nutr. 2011;105(11):1660-70.

43. Sioen IA, Pynaert I, Matthys C, De Backer G, Van Camp J, De Henauw S. Dietary intakes and food sources of fatty acids for Belgian women, focused on n-6 and n-3 polyunsaturated fatty acids. Lipids. 2006;41(5):415-22.

44. Sartorelli DS, Nishimura RY, Castro GS, Barbieri P, Jordão AA. Validation of a FFQ for estimating $\omega-3, \omega-6$ and trans fatty acid intake during pregnancy using mature breast milk and food recalls. Eur J Clin Nutr. 2012;66(11):1259-64.

45. Peng Y, Zhou T, Wang Q, Liu P, Zhang T, Zetterström R, Strandvik B. Fatty acid composition of diet, cord blood and breast milk in Chinese mothers with different dietary habits. Prostaglandins Leukot Essent Fatty Acids. 2009; 81(5-6):325-30.

46. Tokudome Y, Kuriki K, Imaeda N, Ikeda M, Nagaya T, Fujiwara N, Sato J, Goto C, Kikuchi S, Maki S, Tokudome S. Seasonal variation in consumption and plasma concentrations of fatty acids in Japanese female dietitians. Eur J Epidemiol. 2003;18(10):945-53.

47. Ford R, Faber M, Kunneke E, Smuts CM. Dietary fat intake and red blood cell fatty acid composition of children and women from three different geographical areas in South Africa. Prostaglandins Leukot Essent Fatty Acids. 2016;109:13-21.

48. Khan SA, Jackson RT. Polyunsaturated fatty acids, inflammation, and metabolic syndrome in south Asian Americans in Maryland. Food Sci Nutr. 2018;6(6):1575-81.

49. Nagel G, Linseisen J. Dietary intake of fatty acids, antioxidants and selected food groups and asthma in adults. Eur J Clin Nutr. 2005;59(1):8-15.

50. Johansson LR, Solvoll K, Bjørneboe GE, Drevon CA. Intake of very-long-chain n-3 fatty acids related to social status and lifestyle. Eur J Clin Nutr. 1998; 52(10):716-21.

51. Innis SM, Elias SL. Intakes of essential n-6 and n-3 polyunsaturated fatty acids among pregnant Canadian women. Am J Clin Nutr. 2003;77(2):473-8.

52. Friesen RW, Innis SM. Dietary arachidonic acid to EPA and DHA balance is increased among Canadian pregnant women with low fish intake. J Nutr. 2009;139(12):2344-50.

53. Kuriki K, Nagaya T, Imaeda N, Tokudome Y, Fujiwara N, Sato J, Ikeda M, Maki S, Tokudome S. Discrepancies in dietary intakes and plasma concentrations of fatty acids according to age among Japanese female dietitians. Eur J Clin Nutr. 2002;56(6):524-31.

54. Naya $Y$, Ito H, Masai M, Yamaguchi $K$. Association of dietary fatty acids with urinary oxalate excretion in calcium oxalate stone-formers in their fourth decade. BJU Int. 2002;89(9):842-6.

55. Yamada H, Shimizu S, Shinmen Y. Production of arachidonic acid by Mortierella elongata 1S-5. Agric Biol Chem. 1987;51:785-90.

56. Totani N, Oba K. The filamentous fungusmortierella alpina, high in arachidonic acid. Lipids. 1987;22(12):1060-2.

57. Shinmen Y, Shimizu S, Akimoto K, Kawashima H, Yamada H. Production of arachidonic acid by Mortierella fungi: selection of a potent producer and optimization of culture conditions for large-scale production. Appl Microbiol Biotechnol. 1989;31:11-6.

58. Higashiyama K, Yaguchi T, Akimoto K, Fujikawa S, Shimizu S. Effects of mineral addition on the growth morphology of and arachidonic acid production by Mortierella alpina 1S-4. J Am Oil Chem Soc. 1998;75(12): 1815-9.

59. Higashiyama K, Fujikawa S, Park EY, Okabe M. Image analysis of morphological change during arachidonic acid production by Mortierella alpina 1S-4. J Biosci Bioeng. 1999;87(4):489-94.

60. Kikukawa H, Sakuradani E, Ando A, Shimizu S, Ogawa J. Arachidonic acid production by the oleaginous fungus Mortierella alpina 1S-4: a review. J Adv Res. 2018;11:15-22.
61. Okaichi Y, Ishikura Y, Akimoto K, Kawashima H, Toyoda-Ono Y, Kiso Y, Okaichi H. Arachidonic acid improves aged rats' spatial cognition. Physiol Behav. 2005;84(4):617-23.

62. Kotani S, Nakazawa H, Tokimasa T, Akimoto K, Kawashima H, Toyoda-Ono Y, Kiso Y, Okaichi H, Sakakibara M. Synaptic plasticity preserved with arachidonic acid diet in aged rats. Neurosci Res. 2003;46(4):453-61.

63. Fukaya T, Gondaira T, Kashiyae Y, Kotani S, Ishikura Y, Fujikawa S, Kiso Y, Sakakibara M. Arachidonic acid preserves hippocampal neuron membrane fluidity in senescent rats. Neurobiol Aging. 2007;28(8):1179-86.

64. Maekawa M, Takashima N, Matsumata M, Ikegami S, Kontani M, Hara Y, Kawashima H, Owada Y, Kiso Y, Yoshikawa T, Inokuchi K, Osumi N. Arachidonic acid drives postnatal neurogenesis and elicits a beneficial effect on prepulse inhibition, a biological trait of psychiatric illnesses. PLoS One. 2009;4(4):e5085.

65. Tokuda H, Kontani M, Kawashima H, Kiso Y, Shibata H, Osumi N. Differential effect of arachidonic acid and docosahexaenoic acid on age-related decreases in hippocampal neurogenesis. Neurosci Res. 2014:88:58-66.

66. Hosono T, Nishitsuji K, Nakamura T, Jung CG, Kontani M, Tokuda H, Kawashima H, Kiso Y, Suzuki T, Michikawa M. Arachidonic acid diet attenuates brain A $\beta$ deposition in Tg2576 mice. Brain Res. 2015;1613:92-9.

67. Hosono T, Mouri A, Nishitsuji K, Jung CG, Kontani M, Tokuda H, Kawashima $\mathrm{H}$, Shibata H, Suzuki T, Nabehsima T, Michikawa M. Arachidonic or docosahexaenoic acid diet prevents memory impairment in Tg2576 mice. J Alzheimers Dis. 2015;48(1):149-62.

68. Nakano D, Ishii F, Fujii K, Ishikura Y, Akimoto K, Kontani M, Kawashima H, Kiso Y, Matsumura Y. Effects of dietary arachidonic acid supplementation on age-related changes in endothelium-dependent vascular responses. J Nutr Sci Vitaminol (Tokyo). 2007:53(1):75-81.

69. Hirota S, Adachi N, Gomyo T, Kawashima H, Kiso Y, Kawabata T. Low-dose arachidonic acid intake increases erythrocytes and plasma arachidonic acid in young women. Prostaglandins Leukot Essent Fatty Acids. 2010;83(2):83-8.

70. Thies F, Nebe-von-Caron G, Powell JR, Yaqoob P, Newsholme EA, Calder PC. Dietary supplementation with eicosapentaenoic acid, but not with other long-chain n-3 or n-6 polyunsaturated fatty acids, decreases natural killer cell activity in healthy subjects aged $>55$ y. Am J Clin Nutr. 2001;73(3):539-48

71. Kakutani S, Ishikura Y, Tateishi N, Horikawa C, Tokuda H, Kontani M, Kawashima H, Sakakibara Y, Kiso Y, Shibata H, Morita I. Supplementation of arachidonic acid-enriched oil increases arachidonic acid contents in plasma phospholipids, but does not increase their metabolites and clinical parameters in Japanese healthy elderly individuals: a randomized controlled study. Lipids Health Dis. 2011;10:241.

72. Kusumoto A, Ishikura Y, Kawashima H, Kiso Y, Takai S, Miyazaki M. Effects of arachidonate-enriched triacylglycerol supplementation on serum fatty acids and platelet aggregation in healthy male subjects with a fish diet. $\mathrm{Br} \mathrm{J}$ Nutr. 2007:98(3):626-35.

73. Nelson GJ, Schmidt PC, Bartolini G, Kelley DS, Kyle D. The effect of dietary arachidonic acid on platelet function, platelet fatty acid composition, and blood coagulation in humans. Lipids. 1997;32(4):421-5.

74. Innis SM, Hansen JW. Plasma fatty acid responses, metabolic effects, and safety of microalgal and fungal oils rich in arachidonic and docosahexaenoic acids in healthy adults. Am J Clin Nutr. 1996;64(2):159-67.

75. Walker CG, West AL, Browning LM, Madden J, Gambell JM, Jebb SA, Calder PC. The pattern of fatty acids displaced by EPA and DHA following 12 months supplementation varies between blood cell and plasma fractions. Nutrients. 2015;7(8):6281-93.

76. Schuchardt JP, Ostermann Al, Stork L, Kutzner L, Kohrs H, Greupner T, Hahn A, Schebb NH. Effects of docosahexaenoic acid supplementation on PUFA levels in red blood cells and plasma. Prostaglandins Leukot Essent Fatty Acids. 2016;115:12-23. 